\title{
Las formas del holismo. La construcción teórica de la totalidad en etnografía
}

\author{
ÁNGEL DÍAZ DE RADA \\ Departamento de Antropología Social y Cultural \\ UNED. Madrid
}

\section{RESUMEN}

La búsqueda de la totalidad, el holismo, es una de las intenciones básicas de la investigación etnográfica. Este artículo examina la problemática del holismo a través de la revisión de las variadas formas de la totalidad en el desarrollo de la antropología. Los pretextos para este examen se encuentran en Tylor, Malinowski, Mauss, Dumont, Fernandez y Marcus. Estas diversas imágenes de totalidad muestran hasta qué punto la aspiración metodológica del holismo está determinada por los modelos teóricos y morales de la cultura.

Palabras clave: Métodos antropológicos, Holismo, Etnografía.

\section{SUMMARY}

The search for the whole, holism, is one the basic intentions in the ethnographic research. This paper examines the holism and its problems by reviewing the various forms that the whole has taken through the development of Anthropology. The pretexts for this examination are in a series of writings by Tylor, Malinowski, Mauss, Dumont, Fernandez and Marcus. These various images of the whole show the extent to what the methodological aspiration of the holism is determined by theoretical and moral models of the culture.

Key words: Anthropological Methods, Holism, Ethnography.

RDTP, LVIII, 1 (2003): 237-262 
Introdujo sus monedas por la ranura para el billete. Innumerables millones de pasajeros habían sacado brillo con sus caderas a la entrada giratoria. De esto nacía un sentimiento de comunión, de la humana hermandad en una de sus formas más vulgares. Pero Herzog pensó, mientras hacía girar el paso, que aquel símbolo era muy serio pues mientras más individuos se destruyeran mayor sería su aspiración a fundirse en la colectividad. Y el resultado sería aún peor porque estos individuos regresan a la masa agitados, fervientes por su fracaso. No vuelven como hermanos sino como degenerados.

Saul Bellow, Herzog.

En La Lógica de la Investigación Etnográfica presenté con Honorio Velasco el holismo como una operación de conocimiento practicada por el antropólogo, y, en su caso, por el etnógrafo (Velasco y Díaz de Rada 1997). Esto implica que el todo, la totalidad y el holismo son categorías a definir en el nivel de la teoría y el método, no en el nivel del objeto, entendido como realidad pre-teórica. Puesto que el todo no está dado en ninguna clase de realidad pre-teórica (y, como veremos, se precisará de una teoría, en particular de una teoría de la modernidad, para hacerlo aparecer de este modo), las construcciones del todo dependen de los motivos de los investigadores. Esto quiere decir que, como proceso y como producto, el todo de la Antropología no es único. No hay un único todo. Las formas del holismo son diversas. Voy a mostrar esto sirviéndome de una secuencia coyuntural de textos, y al mostrarlo espero ilustrar también algunas de las estrategias típicas de construcción de la totalidad y algunos de los problemas centrales que implican en cuanto a la comprensión de los sujetos sociales.

\section{TYLOR Y EL TODO HUMANIDAD}

La famosa definición de cultura de Tylor en Cultura primitiva, mil veces citada, pretende incluir en el todo literalmente todo lo humano:

La Cultura o la Civilización, tomada en su amplio sentido etnográfico, es ese complejo conjunto que incluye el conocimiento, las creencias, las artes, la moral, las leyes, las costumbres y cualesquiera otras aptitudes y hábitos adquiridos por el hombre como miembro de la sociedad (Tylor 1977: 19).

Esta noción abarcadora de cultura parece extenderse a toda producción de la especie humana en su conjunto, y por tanto exige ser tratada como un conjunto único, por encima de las fronteras de las diversas sociedades. La definición de Tylor continúa: 
La situación de la cultura entre las diversas sociedades de la humanidad, en la medida en que es susceptible de ser investigada según unos principios generales, es una materia adecuada para el estudio de las leyes del pensamiento y de la acción humanos (Tylor 1977: 19).

A esta forma de totalidad que yo denomino el Todo Humanidad, parece satisfacerle el adagio italiano que Tylor cita un poco más adelante: "Todo el mundo es un solo país" (Tylor 1977: 23).

Esta forma de ver el todo está soportada, por una parte, en una premisa epistemológica, la búsqueda de "las leyes del pensamiento y de la acción humanos"; y, por otra, en el modelo moral ilustrado cuya versión empírica dio lugar a una de las aportaciones más preciadas de la moderna antropología: la tesis de la unidad de nuestra especie. Tal como fue formulado por Tylor, este Todo Humanidad conlleva un programa de acción en dos fases. En primer lugar, el ejercicio de descripciones localizadas en diversas sociedades; en segundo lugar, un vasto ejercicio de comparación, que en un futuro, depurada la "complejidad demostrativa" de las ciencias sociales y la "imperfección de sus métodos de observación" (Tylor 1977: 21) habrá de conducir a la formulación de leyes. No se nos escapa que este ideal, diríamos chejoviano del tipo "cuando nos llegue la hora, seremos felices", este formato utópico de perfección científica hunde sus raíces en una visión característicamente decimonónica de la evolución como progreso. Otro supuesto general en esta visión del todo es que los hechos de la sociedad y la cultura son hechos de naturaleza, de manera que la unidad de la Humanidad parece corresponderse con el ideal de una ciencia unitaria. Tal unidad de las ciencias presume, de hecho, una regla de coherencia única entre los objetos de la sociedad y la cultura y los objetos de la naturaleza. Esa regla de coherencia básica entre los objetos, todos los objetos, queda estipulada por Tylor como una relación causal. Como él mismo dice, citando la observación que un jefe bechuana hiciera a un misionero: "Un hecho es siempre hijo de otro, y nunca debemos olvidar el parentesco" (Tylor 1977: 22).

Además de estos supuestos generales, este Todo Humanidad implica otros supuestos de carácter práctico acerca de los materiales etnográficos y su tratamiento.

Para construir su Todo Humanidad Tylor considera a la cultura como un depósito de piezas exentas, extraídas una a una de su contexto concreto de producción, a la manera de un museo clásico:

Examinemos, por ejemplo, - escribe Tylor- los afilados y puntiagudos instrumentos de una colección de ese género; el catálogo incluye hachas, azuelas, cinceles, cuchillos, sierras, rascadores, punzones, agujas, lanzas y puntas de flecha, 
y la mayoría de estos instrumentos o todos pertenecen, con sólo diferencias de detalles, a las razas más diversas (Tylor 1977: 24).

Y esta visión se extiende del campo de las cosas e instrumentos al ámbito de los comportamientos:

Lo mismo ocurre con las ocupaciones salvajes; el corte de leña, la pesca con red o cuerda, la caza mediante el disparo de flechas, la forma de hacer fuego, la cocina, el entrenzado de la cuerda y la confección de cestas, se repiten con sorprendente regularidad en los anaqueles del museo que refleja la vida de las razas inferiores desde Kamchatka hasta Tierra del Fuego, y desde Dahomey hasta Hawaii (Tylor 1977: 24).

Este depósito de piezas, este vasto museo de la Humanidad es, pues, descomponible y clasificable, de manera que finalmente los productos culturales de las diversas sociedades resultan comparables, y eventualmente explicables. La condición de esta operatoria es que tales piezas signifiquen algo para el investigador una vez extraídas de sus contextos locales de producción. "En tales comparaciones - dice Tylor explícitamente- poco respeto es necesario a la fecha en la historia o al lugar en el mapa" (Tylor 1977: 23).

Con estos supuestos queda descrita por Tylor nuestra labor como etnógrafos:

Para el etnógrafo, el arco y la flecha es una especie, el hábito de aplanar los cráneos de los niños es una especie, la costumbre de contar los números por decenas es una especie [...] De igual modo que el catálogo de todas las especies de plantas y animales de una zona representa su flora y su fauna, así la lista de todos los artículos de la vida general de un pueblo representa ese conjunto que llamamos su cultura (Tylor 1977: 25).

Implícitamente se desliza aquí un modelo monádico de totalidades: el Todo Humanidad se compone de todos menores que en su composición interna replican una y otra vez la misma estructura: un catálogo de elementos abstraíbles, como las piezas de un museo, en función de los intereses clasificatorios del investigador. El Todo Humanidad es así construido sobre los cimientos de una cultura consumada, una cultura convertida en el registro de sus productos, y no necesariamente en la comprensión de sus procesos. No en vano, la noción de organización se representa, en el texto de Tylor como un participio: "De este tipo de cualidades generales de instituciones humanas organizadas es de lo que especialmente trata la etnografía" (Tylor 1977: 28. La cursiva es mía). 


\section{MALINOWSKI Y EL TODO LOCAL}

Es conocida la insistencia de Malinowski en otra forma de totalidad, que podríamos llamar el Todo Local, cuyos supuestos epistemológicos y metodológicos son diferentes. En su texto póstumo, Una Teoria Científica de la Cultura, declara: "[Cultura] es [...] el conjunto integral constituido por los utensilios y bienes de los consumidores, por el cuerpo de normas que rige los diversos grupos sociales, por las ideas y artesanías, creencias y costumbres" (Malinowski 1984b: 56). La definición recuerda en amplitud a la de Tylor, pero su énfasis es local, o, como también se ha dicho, insular: lo esencial es la condición "integral" de los "diversos grupos sociales". Y aunque Malinowski no aparca el ideal de una ciencia universalista, pues a la larga su propuesta de una ordenación de las culturas con arreglo a un esquema universal de funciones persigue tal fin, es evidente que, frente a la obsesión de Tylor por un esquema de coherencia trans-cultural de las producciones sociales, Malinowski se encuentra más bien obsesionado por la búsqueda de una coherencia intra-cultural. La obsesión de Malinowski es tomar "una cultura individual como un conjunto coherente" (Malinowski 1984b: 58), y de ahí su furibunda crítica de la idea de Lowie de cultura como una "taracea de harapos y retazos" (Malinowski 1984b: 58). Y en su búsqueda de la coherencia interna de esa isla de experiencia humana de los habitantes de las Trobriand, Malinowski se encontró con el "ambiente artificial o secundario" de las instituciones (Malinowski 1984b: 57), cuyo orden de coherencia no es el de la naturaleza, sino un orden superpuesto: el del significado. Volveré enseguida sobre la importancia de este hallazgo.

A diferencia de Tylor, Malinowski invita a una visión de la cultura como un sistema de procesos en curso, y no como un conjunto de productos terminados. Lo que el investigador percibe como un hecho organizado es, en realidad, lo que la actividad de los hombres de una colectividad ha organizado secundariamente, dando relieve cultural, significativo, a lo que de otro modo sería insignificante: "[...] Una revelación religiosa - dice Malinowski-, o un movimiento estético o moral, permanecen culturalmente intrascendentes a menos que se traduzcan en una serie organizada de actividades cooperativas" (Malinowski 1984b: 64).

En consecuencia, el investigador no debe mirar a los productos culturales como piezas acabadas, sino que debe contemplarlos como objetos de uso, objetos en actividad. La cultura, para Malinowski, no es un vasto museo de piezas sustancializadas, sino un conjunto articulado, integral, de usos sociales. Para referirnos a ellos utilizamos hoy en día con frecuencia la categoría de práctica. 
Este desplazamiento de los productos a los procesos es fundamental a la hora de comprender qué significado dio Malinowski a la noción de significado, y cómo configuró su noción de totalidad. Si el Todo Humanidad pone el énfasis en la operación primaria de abstracción de un contexto local, pues lo que interesa es comparar producciones procedentes de muy diferentes contextos; la operación primaria del Todo Local consiste precisamente en comprender las producciones culturales por su valor en un contexto local determinado, pues es ahí y no en otra parte donde encuentran su uso social, su significado. Cuando la tarea es construir un Todo Local, el aislamiento de las producciones de la cultura sólo puede realizarse, como dijo Malinowski, una vez que esa producción concreta ha sido "definida en la concreta realidad cultural" de que se trate. "Fenómenos tales como la caza de cabezas, extravagantes ritos funerarios [...] pueden ser mejor interpretados como elaboración local de tendencias e ideas esencialmente humanas [...]" (Malinowski 1984b: 60). Esto significa que si para el Todo Humanidad el agente de la coherencia, el que proporciona coherencia a los datos, es básicamente el investigador siguiendo sus propios intereses clasificatorios, y saltando por encima de las elaboraciones locales concretas de su producción; para el Todo Local el investigador debe prestar una atención constante a la propia realidad comunicativa de los sujetos que investiga, pues es esa realidad la que configura su existencia misma como una experiencia de hechos socioculturales, es decir, de instituciones. De ahí, creo yo, el interés de Malinowski por el punto de vista nativo.

Pero lo decisivo de la idea del Todo Local es que ayuda a redefinir el holismo no por la exhaustividad del objeto que construimos (es decir, por la condición de totalidad o parcialidad de nuestro catálogo de piezas, considerada en términos absolutos), sino por lo logrado de nuestro trabajo con los datos, en la dirección de suministrar un contexto, cuando menos, suficiente de interpretación. Es decir, que el holismo queda redefinido como un verbo: suministrar contexto; y de esta manera se revela que cualquier totalidad, cualquier acceso a la totalidad sólo puede estar relativamente conseguida. Esta peculiaridad del Todo Local se comprende mostrando con mayor detalle cómo veía Malinowski la noción de significado. Para ello me serviré de un texto clásico que apostillaba la obra de Ogden y Richards El Significado del Significado: "El problema del significado en las lenguas primitivas" (Malinowski 1984a). La clave se encuentra en este párrafo que cito literalmente:

Todas las palabras que describen el orden social nativo, todas las expresiones que se refieren a creencias nativas, a costumbres, ceremonias y ritos mágicos específicos - todas esas palabras, evidentemente, no existen en inglés, ni en nin- 
guna otra lengua europea. Esas palabras sólo pueden traducirse al inglés no dando su equivalente imaginario - pues evidentemente no puede encontrarse uno real- sino explicando el significado de cada una de ellas mediante una descripción etnográfica exacta de la sociología, cultura y tradición de esa comunidad nativa (Malinowski 1984a: 314-315).

O sea que el acceso al significado de la más elemental de las palabras, por ejemplo, "kula", en tanto ésta toma por objeto a una institución humana concreta, sólo puede conseguirse realizando un recorrido total, holístico, por el conjunto de las instituciones de la vida nativa: el contexto de una palabra trasciende las barreras del contexto lingüístico y pasa a ser concebido como un contexto de situación, y su significado global un recorrido por todos los contextos de situación en los que cabe producirse: "[...] la concepción de contexto — decía Malinowski- debe ser sustancialmente ampliada para que nos rinda su plena utilidad. En efecto, debe quebrar los límites de la mera lingüistica y ser transportada al análisis de las condiciones generales bajo las cuales se habla una lengua" (Malinowski 1984a: 320). A través de esta noción de la vida social como vida de los significados de una colectividad es como apreciamos con la mayor claridad hasta qué punto el Todo Local induce a una representación del significado como práctica y experiencia, una idea del significado que evoca las nociones enactivas de Peirce, Piaget o Bruner, y que exige una descentración de la tradición logocéntrica y referencialista de la significación como un catálogo estático de entradas en un diccionario:

\footnotetext{
El significado de la cosa se constituye mediante experiencias de sus usos activos, y no mediante la contemplación intelectual. Así, cuando un salvaje aprende a comprender el significado de una palabra, este proceso no se cumple mediante explicaciones, sino aprendiendo a manejarla. Una palabra significa para un nativo el uso adecuado de la cosa que representa exactamente como un implemento significa algo cuando puede ser manejado y no significa nada cuando no está a disposición ninguna experiencia de él (Malinowski 1984a: 337).
}

Más allá de exigir una mera traducción referencial, la traducción cultural de las categorías apuntadas en el lenguaje demanda un recorrido por un espacio complejo de prácticas sociales.

En lugar de traducir, de insertar simplemente una palabra inglesa en lugar de una nativa, nos vemos enfrentados con un proceso largo y no del todo simple de descripción de amplios campos de costumbre, de psicología social y de organización tribal, que corresponden a un término u otro. Vemos que el análisis lingüístico nos conduce inevitablemente al estudio de todos los temas que abarca el trabajo etnográfico efectivo (Malinowski 1984a: 316). 
¿Cabe citar mejor antecedente de la noción maussiana de becho social total?

\section{MAUSS Y EL TODO EN El SUJETO}

Al formular la idea de el Todo en el Sujeto intento sugerir que la totalidad, si hemos de prestar atención a la noción de hecho social total formulada por Marcel Mauss en su famoso Ensayo sobre los dones (Mauss 1979), se presenta a sus ojos como una propiedad del sujeto sometido a estudio, y no ya, sólamente, como el efecto metodológico de la aplicación de la etnografía. Esto no significa que el holismo deba ser interpretado como una realidad ajena a la interpretación del antropológo. Lo que significa es que por detrás de la idea de totalidad de Marcel Mauss se adivina una teoría de la modernidad que permite formular la siguiente idea empírica: en una diversidad de épocas y escenarios culturales, cuya única característica común es no ser nuestra época ni ser nuestro escenario, el regalo, el don, pone en evidencia que los nativos han contemplado, ellos mismos, su mundo sociocultural desde una perspectiva holística. O sea que el regalo, como forma de intercambio entre sujetos sociales, es portador de un complejo plexo de relaciones sociales e institucionales, de manera que no puede ser aislado de ese plexo (como sí puede serlo la mercancía capitalista), ni equiparado con una equivalencia estándar, por ejemplo, monetaria. El don vale, no por su precio objetivado y desubjetivado, sino por la posición y la intención social de quien lo da y de quien lo recibe, y por la relación social entre ambos. El don, dice Mauss, no proporciona al otro la posesión de una riqueza, lo que le proporciona es una deuda, o sea, el horizonte hacia futuro de una relación social. Ésta es la expresión de lo que llamo el Todo en el Sujeto:

Desde hace años —escribe Mauss al inicio de su Ensayo-, me he interesado a la vez por el régimen del derecho contractual y por el sistema de prestaciones económicas entre las diversas secciones o subgrupos de que se componen las sociedades llamadas primitivas, así como las que podríamos denominar arcaicas. Hay una variedad enorme de ellos, muy complejos, donde todo queda mezclado, todo cuanto constituye la vida propiamente social de las sociedades que han precedido la nuestra -incluidas las de la protohistoria-. En ese fenómeno social "total", como proponemos denominarlo, se expresan a la vez y de golpe todo tipo de instituciones: las religiosas, jurídicas, morales -en éstas tanto las políticas como las familiares- y económicas, las cuales adoptan formas de producción y consumo, o mejor de prestación y distribución, y a las cuales hay que añadir los fenómenos estéticos a que estos hechos dan lugar, así como los fenómenos morfológicos que estas instituciones producen (Mauss 1979: 157). 
A partir de este punto, la propuesta holística de Mauss consiste en perseguir las formas de la concreta institución de la prestación y la contraprestación, como hubiera deseado Tylor, "desde Kamchatka hasta Tierra del Fuego, y desde Dahomey hasta Hawaii" (y, habría que añadir, desde los actuales Kwakiutl hasta los arcaicos patricios romanos); pero, como habría deseado Malinowski, sin olvidar nunca el sentido específico de tal institución y su intrincada red de relaciones interinstitucionales en cada uno de los contextos locales. El resultado es un memorable ejercicio etnohistórico que conduce, parafraseando a Geertz, a contemplar el universo del intercambio en la gota de agua de una sencilla acción recíproca: ofrecer un don, aceptar un don. Este todo no apela por tanto a la noción de organicidad de un modelo insular de la cultura (pues lo que se somete a examen es una forma de institución transcultural), ni arrastra consigo la inevitable arbitrariedad de las ideas tylorianas acerca de lo que debe ser clasificado (ese cajón de sastre que recuerda a los antiguos museos), pues esta gota de agua no es cualquier gota de agua (un cráneo reducido, una punta de lanza, un arco y una flecha). Esta gota de agua contiene el objeto nuclear de cualquier examen antropológico: las formas de la vinculación social, es decir, es una gota de agua relacional:

Incluso aunque expongamos con precisión los principios diversos que han dado este aspecto [de don, de regalo] a una forma necesaria del cambio [...], sólo estudiaremos a fondo uno: ¿cuál es la norma de derecho y de interés que ha hecho que en las sociedades de tipo arcaico el regalo recibido haya de ser obligatoriamente devuelto? ¿Qué fuerza tiene la cosa que se da, que obliga al donatario a devolverla? (Mauss 1979: 157).

La mejor ilustración del hecho de que para Mauss el holismo es algo más que una premisa metodológica, convirtiéndose en una propiedad empírica de las sociedades que él denomina primitivas o arcaicas, es precisamente que al señalar el don como institución holística presume que existen formas de institución que, como el mercado capitalista, no lo son. Esto nos llevaría a la idea, apuntada en alguna ocasión por su discípulo Lévi-Strauss y sobre todo por Louis Dumont, de que al contemplar sus objetos de interés desde una perspectiva holística, el antropólogo contradice, en cierto modo, los ideales de segmentación funcional y fragmentación institucional propios de la ciencia moderna especializada, haciendo suyos los principios de composición de la realidad propios de los arcaicos y los primitivos. Los antropólogos construyen, en consecuencia, una ciencia incómoda, que busca síntesis donde, por ejemplo la sociología moderna buscaría análisis, y que, como hemos indicado en La Lógica de la Investigación Etnográfica, tiende a producir complejidad antes que sim- 
plificación (Velasco y Díaz de Rada 1997). En todo caso, sea lógicamente, como una operación del investigador, o metalógicamente, como una operación de los nativos interpretados por el investigador, es relativamente fácil identificar, en el Ensayo sobre los dones, qué hace que una institución, o sea, un interpretante social, sea holístico. He aquí sus criterios.

Una institución -una perspectiva acerca del mundo- es holística cuando se construye sobre algún principio de integración de las relaciones sociales, y de hecho, cuando su objeto de interés no es tanto un objeto sustancializado cuanto una relación entre sujetos: "Este tipo de derecho y Economía — dice Mauss refiriéndose a los de las sociedades primitivas y arcaicas - contiene diversos temas, ideas y reglas. El más importante de estos mecanismos espirituales es evidentemente que obliga a devolver el regalo recibido" (Mauss 1979: 162. La cursiva es mía).

Asimismo lo es cuando opera, además, por replicación, como la regla de un código, en diversas parcelas de la vida: "[...] En Samoa, el sistema de regalos contractuales se extiende a otros hechos además del matrimonio. Acompaña a los siguientes acontecimientos: nacimiento de un niño, circuncisión, enfermedad, pubertad de la mujer, ritos funerarios y comercio" (Mauss 1979: 163).

En tercer lugar, una institución - una perspectiva acerca del mundoes holística cuando implica un ejercicio semiótico (de representación) en relación con el agente que la pone en práctica, es decir, cuando no es posible aislarla del sujeto que la realiza, contemplado en su totalidad, a riesgo de perder su sentido:

Por el momento lo que ha quedado claro es que para el derecho maorí, la obligación de derecho, obligación por las cosas, es una obligación entre almas, ya que la cosa tiene un alma. [...] Se comprende clara y lógicamente que, dentro de este sistema de ideas, hay que dar a otro lo que en realidad es parte de su naturaleza y sustancia, ya que aceptar algo de alguien implica aceptar algo de su esencia espiritual, de su alma (Mauss 1979: 168).

En realidad esta propiedad de las instituciones holísticas se encuentra intrínsecamente relacionada con la anterior, pues precisamente porque las cosas van con sus agentes, como expresiones de su "sustancia", representándolos, esta representación de sus posiciones sociales se replica por allí por donde sus cosas circulan: el mundo es una expresión replicada, una y otra vez, de los sujetos que lo componen y de los productos de su actividad a ellos asociados. Las cosas, en términos sociales, son ante todo significantes de relación social, significan porque hablan de las relaciones, y por eso las cosas, cuando son socializadas, nunca son neutras, siempre significan y lo hacen con estilo, o, como diría Bourdieu, con habitus. 
En consecuencia, una institución - una perspectiva- es holística (un hecho social es total), cuando se extiende representacionalmente más allá de los límites de cada producción concreta, por encima de las segmentaciones analíticas: de la economía al arte, del arte al parentesco, de la esfera jurídica a la religiosa: "No es puro azar que las dos fórmulas solemnes del contrato: en latín do ut des, y en sánscrito dadami se, debi me, se han conservado también a través de los textos religiosos" (Mauss 1979: 175).

Construir el Todo en el Sujeto, en el primitivo y arcaico sujeto de la Antropología, lleva a Mauss, inevitablemente, a cuestionarse por la condición de la sociedad propia, y en este ejercicio alegórico se adivina el descubrimiento de nuestro propio individualismo.

La legislación francesa de seguridad social —escribe Mauss al final de su Ensayo sobre los dones-, ese socialismo estatal ya palpable, se inspira en el siguiente principio: el trabajador da su vida y su trabajo, por un lado, a la colectividad y por otro a sus patrones; así, aunque tengan que colaborar en la obra de seguridad, quienes se han beneficiado no quedan liberados por el pago del salario; el Estado, representante de la comunidad, les debe junto con sus patronos y su propia ayuda, una cierta seguridad en la vida, contra el paro, la enfermedad, la vejez y la muerte (Mauss 1979: 248).

En esta transición aprecia Marcel Mauss un ejercicio de rectificación de las sociedades contemporáneas, el ejercicio de rectificación que la reflexión más reciente exige de la moderna burocracia y del moderno capital: una llamada de atención hacia una visión relacional de la vida. Él lo expresó con la imagen de un retorno: "Volvemos pues a una moral de grupos". Un retorno que, por ejemplo, Pietro Barcellona ha tematizado, hace sólo una década, como "El regreso de la vinculación social" (Barcellona 1992). Louis Dumont representa el primer movimiento de este retorno reflexivo: el Todo está en los Otros; James Fernandez, el segundo: en busca del Todo Perdido; George Marcus, el tercero: el Todo Reconstruído en la Fragmentación.

\section{DUMONT: EL TODO ESTÁ EN LOS OTROS}

En una conferencia de 1980 publicada en español en su colección de Ensayos sobre el Individualismo, que lleva por título "El valor en los modernos y en los otros" (Dumont 1987), Louis Dumont continúa el trayecto iniciado por Marcel Mauss, aportando nuevas dimensiones al problema del holismo. Para Dumont, la modernidad es eminentemente un plexo de instituciones regidas por un código central: el individualismo. El individualismo es una forma particular de producción cultural que consis- 
te en practicar la regla inversa del holismo: no es la relación lo que prima, como objeto de interés, sino el individuo sustancializado como entidad autónoma. No es, de hecho, un código local de replicaciones semióticas el que constituye la regla de la acción, sino un dispositivo universal de carácter sistémico, que actúa según un modelo maquinístico: el sistema de mercado (como sistema de sistemas) con su imperturbable ley de hierro, su ley natural. No es la relación intrínseca entre el sujeto y sus producciones lo que se considera relevante, sino su escisión teórica, pues en un sistema naturalizado sólo se trata de que se cumplan las funciones en un régimen de equivalencia funcional. Para tales sistemas, por ejemplo, el laboral, cualquier sujeto concreto es sustituible en el ejercicio de la misma tarea. Y, finalmente, el mundo no se representa como una unidad de acción y valoración, en todas sus dimensiones, sino como un universo fragmentario que se produce y se reproduce en la propia fragmentación de sus instituciones y en la imagen de un saber sobre el ser humano recortado en disciplinas especializadas: el Ministerio de Trabajo, el Ministerio de Economía, el Ministerio de Ciencia y Tecnología y, lo que puede ser más sorprendente, el Ministerio de Asuntos Sociales, jel Ministerio de Cultura!

O sea que Dumont certifica lo que Mauss ya sospechaba: si está en alguna parte, el Todo está en los Otros. Y sólo por la vía de este reconocimiento, que supone una indagación histórica en nuestra constitución cultural como "individuos", podremos, como mínimo, tomar alguna posición acerca del holismo. Podremos, tal vez, considerar, que la construcción de totalidades es ya imposible, o podremos apreciar qué es lo que tiene de falacia este supuesto régimen individualista. Louis Dumont se ha dedicado a hacer esta indagación.

La noción clave en el texto de Dumont es la noción de valor, aunque sólo sea porque, a diferencia de la noción de individuo y en contraposición con ella, sitúa inmediatamente el debate acerca de la consistencia del mundo social en el terreno, abonado por Mauss, de las relaciones entre los sujetos, y no en el de sus identificaciones sustanciales. El valor sólo puede ser relacional. Se lo mire como se lo mire, no es algo que se pueda ver. El valor es, por citar un viejo modelo de Leach, como el valor tonal de las notas musicales, una relación entre ellas, que no está en ellas, pero las hace ser ellas. Y el primer señalamiento empírico de Dumont es que a los modernos, en consecuencia, el valor nos incomoda: "No es nada extraño que el vocablo tenga algo de fastidioso. Al ser esencialmente comparativo, parece condenado a la vacuidad: una cuestión de valores no es una cuestión de hecho" (Dumont 1987: 243). Mas por ser relacional - esto ya lo aprendimos con Malinowski- el valor nos exige un recorri- 
do holístico. "Sacamos la conclusión un poco desagradable de que una comparación profundizada y sólida de los valores sólo es posible entre dos sistemas considerados como todos. Si más tarde queremos introducir una clasificación, deberá partir de todos, y no de los elementos enumerados" (Dumont 1987: 249). De hecho, el valor surge como objeto de reflexión sólo si nos situamos en una perspectiva que pone sobre el tapete al menos dos sistemas de valoración. Ahora bien, y de este modo el problema retorna a una dimensión eminentemente metodológica, ¿cómo podremos sobreponernos los modernos, y así, los antropólogos modernos, al individualismo que nos constituye, si nuestra meta es aspirar a la construcción de totalidades? La pregunta es buena, esencialmente porque no garantiza una respuesta. La respuesta que da Dumont cobra la forma (que apreciaremos con mayor énfasis en James Fernandez) de un intento de restitución: se trata, en sus propios términos, de acceder a "El punto de vista no moderno que trato aquí de restituir" (Dumont 1987: 256): "Nuestro problema es el siguiente: ¿cómo podemos realizar una transición entre nuestra ideología moderna, que separa valores y "hechos", y las demás ideologías, en las que los valores están "imbricados" en la concepción del mundo?" (Dumont 1987: 253). Seguiré con Louis Dumont, brevemente, la misma estrategia de lectura. interesada de su texto que he seguido con Mauss, mostrando los elementos que constituyen el Todo de los Otros.

En primer lugar, el Todo de los Otros (el ejemplo etnográfico nuclear de Louis Dumont es el sistema de castas de la India), implica la relevancia de las relaciones entre elementos, de manera que, en relación con el todo constituido por esos elementos, los elementos mismos establecen entre sí, inevitablemente, relaciones de diferente naturaleza. Esto quiere decir que, en un todo, en el Todo de los Otros que Dumont aspira a restituir, las relaciones no son simétricas, son siempre asimétricas; y que, además, nunca son igualitarias, sino jerárquicas. Prestemos mucha atención: no es que los elementos sean asimétricos y estén ordenados jerárquicamente (esto sucederá en todo caso, por el efecto que sobre ellos realiza su relación en un todo, del mismo modo que el tono Do en relación con el tono Mi, sólo es dominante en un sistema de acorde específico, que le confiere tal valor, pero no en cualquier sistema), sino que son las relaciones las que se ordenan de ese modo. Dumont lo dice así, jugando con las manos:

Derecha e izquierda, al mantener una relación diferente con respecto al cuerpo (una relación derecha y una relación izquierda, por así decirlo) son diferentes en sí mismas. (No son dos entidades idénticas situadas en distintos sitios, como muy bien nos indica nuestra experiencia sensible). Como partes diferentes de 
un todo, derecha e izquierda difieren tanto en valor como en naturaleza, ya que la relación entre parte y todo es jerárquica, y una relación distinta significa aquí un lugar distinto dentro una jerarquía. Es así como las manos y sus tareas o funciones son al mismo tiempo diferentes y, respectivamente, superior e inferior (Dumont 1987: 254).

A partir de este punto, Dumont señala tres características de una configuración de valor, tres características del Todo de los Otros, que yo sugiero considerar como tres propiedades de la vida social a las que debemos estar atentos si lo que perseguimos es la construcción de una totalidad (o sea, si trabajamos con una intención holística).

En primer lugar, la jerarquía implica englobamiento:

Las ideas "superiores" [en su relación de valor con las inferiores] contradicen e incluyen a las "inferiores". He llamado a esta relación tan especial "englobamiento". Una idea que crece en importancia y en status adquiere la propiedad de englobar a su contrario. Es así como he descubierto que en la India la pureza engloba al poder (Dumont 1987: 258-259).

Y es así como también, haciendo uso de su reflexión sobre el holismo y el individualismo, en un hermoso juego de espejos, al lector le habrá quedado claro al final de su texto que el individualismo moderno no es sino una forma particular de holismo. Es decir, que su configuración de valor consiste en la negación del valor, y que esto se debe a una particular disposición y trayectoria de sus instituciones: "Estamos comprometidos en la tarea de reintegrar el caso moderno en el caso general" (Dumont 1987: 253).

En segundo lugar, la jerarquía es, en el Todo de los Otros, bidimensional (Dumont 1987: 259) y funciona por inversión en función de la asimetría de los campos sociales que genera: "En materia de religión, y por lo tanto de manera absoluta, el sacerdote es superior al rey o al emperador, a quienes se les confía el orden público, pero al mismo tiempo, el sacerdote obedecerá al rey en materia de orden público, es decir, en un dominio subordinado" (Dumont 1987: 259).

Finalmente el Todo de los Otros es segmentado, es decir, no se expresa siempre de una forma homogénea e idéntica sí misma. Esto quiere decir que, empíricamente, el valor funciona como una pragmática de relaciones, de manera que los sujetos acentúan unas u otras situacionalmente:

Como decía a propósito de la India, las distinciones [de valor, las distinciones sociales] son numerosas, fluidas, flexibles, "transcurren independientemente las unas de las otras en una red de poca densidad"; están también diversamente acentuadas según las situaciones, situándose a veces en primer plano y difuminándose en otras. Por lo que a nosotros respecta, pensamos la mayoría de 
las veces en blanco y negro, extendiendo sobre un vasto campo claras disyunciones (o bien, o bien) y utilizando un corto número de fronteras rígidas, espesas, que delimitan sólidas entidades (Dumont 1987: 260).

El contraste que establece esta propiedad de segmentación entre los modernos y los otros evoca, de forma inmediata, en nuestro propio mundo, el contraste que podría hacerse entre el universo social de las clasificaciones burocráticas, con su ordenación trans-situacional de roles estancos, y el universo difuso de las relaciones de amistad, con su ordenación oportunista y fluida, dependiente de la situación y del caso, según las prácticas revelen una mejor o peor adecuación al ideal moral. Del mismo modo, el Todo de los Otros es segmentado porque en él la parte no está rígidamente separada del Todo, sino que tiende a confundirse con él en una relación de continuidad, que despunta sinuosamente, situacionalmente, allí donde la práctica social pone en evidencia una más o menos lograda representación de la totalidad. Este concepto ha sido representado, según Dumont, en la cosmovisión hindú, por La Gran Cadena del Ser: "La meta de la jerarquía es [...] en la medida de lo posible, una asimilación y unión con Dios" (Dumont 1987: 262).

Englobamiento, inversión y segmentạción constituyen el Todo de los Otros, el que, según Dumont, una ciencia social holística debe restituir en el examen de todas las sociedades, incluida la propia. Hacer caso a Dumont en lo que tiene de programa para la reimplantación de una visión holística en el sujeto moderno, significa, para el antropólogo, adoptar una cierta disciplina, realizar un reaprendizaje para evitar los tics de una ciencia individualista: para evitar, por ejemplo, la obsesionante persecución de simetrías, propia del diseño experimental o de las encuestas muestrales; para evitar la sustancialización del individuo y la proyección de nociones funcionales transversales a cualquier campo de acción indiferenciadamente, como se practica, por ejemplo, en el análisis luhmanniano de sistemas; para evitar la descripción de las realidades institucionales como programas ideales de acción que sólo groseramente pueden dar cuenta de las segmentaciones, ambigüedades y fronteras porosas del mundo concreto de la vida, como sucede en el caso de las proyecciones tecnocráticas que uno puede encontrar en los informes ministeriales, los diseños curriculares educativos, los sólo aparentemente sólidos esquemas organigráficos de determinada sociología de las organizaciones. 
FERNANDEZ: EN BUSCA DEL TODO PERDIDO

Siguiendo este hilo de historia coyuntural para pensar sobre el holismo y las formas del Todo, me centraré a continuación en un texto de James W. Fernandez, cuyo título es elocuente por sí mismo: "The Argument of Images and the Experience of Returning to the Whole" (Fernandez 1986). Por el bien de mi propia argumentación, espero que no sea mera coincidencia el hecho de que el propio Fernandez introduce su texto con tres referencias inspiradoras: la famosa definición de cultura de Tylor, una sentencia de Lévi-Strauss en Lo crudo y lo cocido acerca de la intrínseca relación entre metáfora y totalidad, y la formulación del "problema esencial del pensamiento contemporáneo" tal como fue definido por Louis Dumont en Homo Hierarchicus: "El problema esencial del pensamiento contemporáneo es descubrir el significado de las totalidades". Éste es pues el problema.

En realidad, el grueso del texto de Fernandez se centra en dar cuerpo a la segunda de esas tres referencias. Aunque la respuesta es compleja y seguramente imposible, la pregunta de Fernandez vuelve a ser simple: ¿en qué se cifra, de qué está hecha, la experiencia de totalidad de los otros?, y la consecuencia metodológica, cristalina: ¿Hasta qué punto estamos nosotros, los antropólogos y etnógrafos académicos, dotados de los medios retóricos y expresivos necesarios para recoger y representar esos sentidos de totalidad? Vemos, pues, que en el trayecto que vengo describiendo las imágenes del Todo han experimentado una reformulación fundamental: el Todo Humanidad y el Todo Local son categorías proyectadas por una ciencia que se cree posible; el Todo en el Sujeto y el Todo en los Otros son categorías críticas que obligan a reconocer las carencias del lenguaje de nuestra ciencia y nuestra cultura, y fuerzan un ejercicio de restitución. El planteamiento de Fernandez, en busca del Todo Perdido, implica la propuesta de un enriquecimiento de nuestros discursos analíticos en la dirección de una renovación de nuestros instrumentos de categorización y, lo que es más importante, representación de la totalidad. Fernandez formula así su propósito:

Me ocuparé de ofrecer un relato de los mecanismos que conducen a la convicción de la totalidad [wholeness] primariamente, aunque no sólamente, en [cuatro] movimientos de revitalización. Etiquetaré, del modo más general, el trabajo que realizan estos mecanismos como "el argumento de imágenes" y sostendré que la convicción de totalidad es el producto de ciertas clases de actividad imaginativa —es decir, visualizadora y pictórica [pictorizing] (Fernandez 1986: 159). 
El punto de partida es el mismo que el de Dumont:

La expresión de Cassirer "la consanguinidad de las cosas" nos recuerda que "el todo", sea lo que sea, es un estado de relacionabilidad [relatedness] —una especie de compañerismo de experiencia. Las sociedades modernas, tan enormemente controvertidas, están, por naturaleza, alienadas de un tal compañerismo abarcativo; niegan el problema fundamental de la relacionabilidad - que es, en mi opinión, el problema central del todo. Pero los movimientos de revitalización de la clase que consideraré aquí - y quizás todas las religiones-están fundamentalmente interesados en restaurar la relacionabilidad de las cosas (Fernandez 1986: 162).

Para explorar los mecanismos de la experiencia (y la convicción) de totalidad, Fernandez ofrece cuatro instantáneas rituales de sendos movimientos de revitalización en África: los Tadzewu de Ghana, una comunidad religiosa de los Apóstoles de la Revelación; los Cristianos Celestiales en Togo, Dahomey; una celebración de Bwiti en Gabón; y algunos grupos de Sionistas en Natal, Zululandia. Como se trata de mostrar un argumento de imágenes, lo mejor será seleccionar uno de estos pasajes de Fernandez, el de Bwiti, que traduzco al español:

A continuación, figúrese la espesa selva ecuatorial de Gabón, en el África ecuatorial occidental, y una aldea alargada y estrecha con dos filas de cabañas, una frente a otra. Hace algún tiempo la aldea fue desbrozada de selva, y la vegetación vuelve de nuevo a echarse sobre ella. En un extremo de la aldea, muy cerca de la selva, se encuentra la capilla de la religión Bwiti. Durante el día, cuando el sol golpea el polvoriento patio, justo a las tres de la tarde, una falange de sus miembros, en filas de tres al frente, en una serie de entradas, danza avanzando desde posiciones alejadas de la periferia del patio al centro de la capilla. Van ataviados con uniformes sueltos en rojo y blanco - blanco sobre la mitad superior de sus cuerpos, la mitad pura, y rojo sobre la mitad inferior, impura y pasional. Los hombres y las mujeres visten exactamente del mismo modo, con dos excepciones: el líder de la capilla —el Huevo de Papagayo, el Gran Cazador- va vestido totalmente de rojo, y el guardián de la capilla, así como el tocador del arpa, visten totalmente de blanco. El líder, que elimina los pecados de los miembros, danza al lado izquierdo de la falange, el lado femenino; el guardián de la capilla, que mantiene la pureza de la noche, danza al lado derecho, el lado masculino. Esta distribución en lados se repite una y otra vez durante las ceremonias que se celebran a lo largo de toda la noche, pues en la capilla hay un lado masculino y un lado femenino, una cámara secreta para los hombres y otra para las mujeres. Además, el culto en su totalidad sólo puede conseguirse al danzar a ambos lados de la capilla y al ejecutar la contradanza de los hombres en el lado femenino y de las mujeres en el lado masculino. Debemos saber también que la capilla es visualizada como un cuerpo sagrado que sólo puede traerse a la existencia -incorporarse, por decirlo así - por la totalidad de estas danzas de entrada y salida. El ejercicio de los orificios de esta capilla microcósmica, la celebra- 
ción interactiva de sus partes, su organización en lados, crean conjuntamente el macrocosmos religioso.

Debemos representar también la dimensión vertical: el árbol adzap de corteza roja, el más alto de los árboles de la selva ecuatorial, en una arboleda no lejos de la capilla. Este árbol es la ruta de los ancestros: ellos van y vienen entre la parte alta y la parte baja. Este árbol y esta ruta se representan por medio de la columna central, cargada con un significado simbólico que se espesa en las representaciones esculpidas, cuya lectura completa - una lectura de todas las asociaciones disponibles - nos conduciría seguramente fuera del universo Bwiti. Durante las danzas nocturnas los miembros tocan frecuentemente esta columna, porque ello los mantiene en contacto con lo de abajo y con lo de arriba, así como sus danzas y contradanzas de entrada los mantienen en contacto con las dos dimensiones horizontales de su espacio de cualidad. Justo a la medianoche, precisamente en el exterior de la capilla, los miembros se encuentran en una larga fila, cada cual sosteniendo una vela. Lentamente, dirigidos por el arpa del culto, danzan en fila hacia el exterior, adentrándose en el espeso bosque por caminos previamente desbrozados. Pronto, el bosque se los traga, y todo lo que podemos ver y oír es el vislumbre ocasional de una vela, un acorde tenue de arpa. Más tarde, regresan; y situándose justo a la entrada y al lado del pilar central, comienzan a ovillarse vigorosamente, en dos partes, en un círculo cada vez más compacto hasta que todos los miembros han sido atraídos y ahora sus velas, sostenidas sobre sus cabezas, forman una gran llama danzante. Esto es nlem mvore, existir en un solo corazón, una de sus principales imágenes de la totalidad de su comunión - una experiencia conseguida de otro modo cuando los danzantes danzan juntos hacia una aldea total, hacia un bosque total, microcosmos y macrocosmos. El culto concluye con un círculo final justo antes de la salida del sol. Después los miembros se reúnen en un pabellón techado en paja en estado de elevada euforia y compañerismo, para tomar la comida matutina de mandioca (Fernandez 1986: 167-168).

Ya lo hemos visto, pero podemos reiterarlo pobremente en un intento de comprensión analítica: los otros acceden a la experiencia de totalidad por medio de tales "argumentos de imágenes", conjuntos de acción expresiva organizada que componen, en la práctica, es decir, en un cuerpo de prácticas, totalidades sociales y cosmológicas. El problema, naturalmente, radica en la comprensión analítica, que tal vez, por el hecho de serlo, se encuentra impedida de entrada no ya para la interpretación de los datos, sino para su simple representación (o sea, para el desplazamiento de la realidad vivida a alguna clase de registro).

Por tanto, -escribe Fernandez - es importante para mi argumento visualizar aspectos seleccionados de estos movimientos. Ello nos aportará algunas de las imágenes básicas por medio de las cuales estos movimientos revitalizan... por medio de las cuales reconstituyen su mundo. Es cierto que desde la perspectiva de los procedimientos de descubrimiento de una ciencia normal del comportamiento, la pictorialización puede parecer inadecuada; en lugar de esto, se esperaría de nosotros que mostrásemos las ideas elementales que subyacen a estas imágenes y 
los comportamientos asociados a tales ideas; mi argumento, sin embargo, es que las imágenes mismas son elementales y primordiales (Fernandez 1986: 169).

Con esta intuición, presentada como argumento fuerte, Fernandez nos dice lo que ya venía despuntando desde Marcel Mauss: la totalidad, la experiencia de totalidad, la construcción de la experiencia de totalidad, y la representación de tal experiencia, son todas ellas problemáticas para los recursos expresivos disponibles en la "ciencia normal", o sea, la ciencia de nuestra sociedad controvertida. Y sólo una renovación de tales recursos podrá capacitarnos para una nueva captación, esta vez crítica y reflexiva, de la totalidad en sus propios términos. El objeto de la crítica de James Fernandez es la traducción intelectualista de las imágenes enactivas que dan lugar a la experiencia de totalidad, y, por tanto, la desvirtuación de su cualidad de experiencia. Pero su propósito es también ilustrar, por medio de estos argumentos de imágenes, la naturaleza incoada de la totalidad, es decir, su carácter abierto e inconcluso, incipiente, pues, a diferencia de los lenguajes analíticos que reducen la experiencia a un conjunto de ideas elementales asociadas a comportamientos, y cuyo sentido pragmático es cerrar sentido por medio de una clausura conceptual, las imágenes en acción que conducen al todo, conducen en realidad a un horizonte de totalidad nunca alcanzado. Ya veíamos, en el Todo Local de Malinowski, un todo relativo; ahora vemos un todo inalcanzable. Una propiedad que yo desearía formular explícitamente para referirme al camino etnográfico: el holismo sólo puede ser una intención más o menos lograda.

La búsqueda de las Elementargedanken - dice Fernandez- [...] evalúa inadecuadamente la experiencia de coherencia y totalidad, que es una experiencia tanto horizontal como jerárquica, periférica y central, interior y exterior -una experiencia de afinidad y consanguinidad, por decirlo así. Como mínimo esta clase de investigación asigna a los procesos profundos de pensamiento $-\mathrm{O}$ a aquellos procesos de pensamiento que tienen que ver con la relacionabilidad- una explicitación y claridad ideacional que no poseen. Los participantes pueden estar al alcance de tales ideas, pero su alcance excede inevitablemente su captación. Tales cosas son incoadas (Fernandez 1986: 170).

Fernandez lleva años buscando el lenguaje renovado de una Antropología al alcance de la totalidad, que es, según él mismo ha propuesto, el lenguaje de los tropos. $\mathrm{Y}$ todo lo que habría que decir al respecto es que, en lo relativo a una metodología reflexivamente fundada, como etnógrafos deberíamos ser sensibles a la cualidad tropológica de la vida social, es decir, a su permanente juego de imágenes en desplazamiento, lo que presupone, desde luego, una previa comprensión de la Antropología como ciencia del significado. 
Al respecto de los movimientos religiosos que hemos presenciado, es fácil reconocer ciertos tropos recurrentes —en su mayor parte metáforas, a veces metonimias- que, en su condición de tropos no sólo son enunciados sino que también pueden ser interpretados [performed] organizando así, satisfactoriamente, una actividad considerable en la comunidad religiosa particular (Fernandez 1986: 171).

El tropo, por antonomasia la metáfora, implica un desplazamiento de sentido, pero, como señala Fernandez implica también un salto de nivel: dos términos en contigüidad sintagmática conducen, ejerciendo en la metáfora, hacia la captación intuitiva del paradigma como totalidad; pues es el paradigma, es decir, el conjunto total de las asociaciones entre significados en varios dominios, el que es evocado, si es que la metáfora ha de tener sentido.

A veces - escribe Fernandez- la asociación de imágenes en la performance ritual es de analogía continua: A : B :: B : C :: C : D ... - La gente es a los árboles como los árboles son al bosque como el bosque es al mundo... Pero, más a menudo, lo que encontramos es la producción de una secuencia de dominios de performance por analogía discontinua: $\mathrm{A}: \mathrm{B}:: \mathrm{C}: \mathrm{D}$. Aquí la estructura relacional -las contigüidades existentes en un dominio de experiencia sugieren, por analogía, la estructura relacional existente en otro dominio de experiencia: la relación de una persona con su clan es como la relación del árbol con el bosque; o el corazón es al cuerpo lo que el centro del círculo es al círculo [...]. En el juego de las analogías discontinuas en el ritual, lo que ocurre es que al ejecutar las experiencias contiguas de un dominio surge un sentido de resonancia o de relación por analogía con alguna parte o partes relacionadas de las estructuras contiguas de otro dominio (Fernandez 1986: 175-176).

James Fernandez recurre a un ejemplo musical para comprender el salto de nivel que produce la metáfora en acción:

Elegimos o nos vemos forzados a ver desde otra perspectiva lo que es continuo en nuestra experiencia en curso - en términos musicales, elegimos otra clave. Una secuencia contigua o sintagmática puede ser transformada, por permutación paradigmática, en otro modo de expresión, y viceversa. Esta metamorfosis, esta transformación interactiva de la sintaxis y el paradigma, la metáfora y la metonimia, es fundamentalmente lo que está en juego cuando se trata de partes relacionadas en relación con todos, universalizaciones en relación con particularizaciones. Y tal metamorfosis resulta ser convincente en su totalidad (Fernandez 1986: 174).

La etnografía facilita en su propio proceso de construcción el acceso a la totalidad porque amplía al máximo las fuentes y perspectivas desde las que se construyen sus datos, y porque trabaja con un horizonte abierto de registro, cuya clausura conceptual está sólo relativamente predetermi- 
nada. Pero nada de esto es suficiente; lo que resulta crucial en la configuración holística del texto etnográfico es su capacidad para practicar ese salto de clave: de la contigüidad sintagmática de las experiencias de campo, que son inscritas en el diario en su curso continuo, a la relación paradigmática de los interpretantes teóricos o conceptuales, que, al hilo del proceso de categorización del investigador, introducen en las experiencias de campo un tiempo de lectura desde el que intuir el código completo que da sentido a cada experiencia particular. Pues, cuando EvansPritchard contempla a un zande practicar el oráculo del veneno, no se trata sólo de ver si muere o no muere una gallina, ni siquiera de apreciar las consecuencias que tal hecho puede tener para la vida práctica de un sujeto, o de muchos sujetos, sino de saber presentar esta acción particular, vivida a su debido tiempo, en el tiempo sin límites de la interpretación teórica: el oráculo del veneno, contemplado en sistema y estructura argumental, se entiende entonces como la puesta en práctica de una forma de racionalidad completa, una forma de cultura.

Desde que el Todo comenzó a ser concebido, primero como un logro del sujeto de la acción social, y después, con mayor precisión, como un logro de los otros, proponiéndose con ello por reflejo una teoría de la modernidad de matriz individualista, la reflexión sobre el holismo no puede ya desprenderse de este juego de espejos, de esta relación relativa entre las posiciones del sujeto de la acción y el sujeto de la investigación; y en consecuencia, la reflexión metodológica (es decir, la que versa sobre la acción del investigador) no puede ya desprenderse del conocimiento de los otros, y de la relación con sus universos morales.

\section{Marcus y el TODO Reconstruído en la Fragmentación}

Esto ya lo sabíamos, sabíamos desde el principio que el holismo es una re-construcción practicada, en todo caso, por el investigador, e incluso cuando se ha apuntado como una experiencia empírica de los otros, esto ha tenido que hacerse proponiendo un punto de vista (holístico) acerca de la configuración de nuestro mundo: una teoría de la modernidad. Pero es precisamente la radicalización de las condiciones de producción de experiencia individualista de la modernidad, en la modernidad tardía, la que nos permite ver con la mayor nitidez hasta qué punto puede ser ingenuo pretender que el Todo está ahí, listo para ser descubierto. Es precisamente la evidencia de una difuminación empírica de las comunidades locales, a las que, independientemente de la novedad del hecho, hoy contemplamos más que nunca atravesadas por un sistema 
mundo translocal, la que pone en evidencia que ya ni en los otros puede sustancializarse la experiencia de totalidad. Lo que tenemos hoy en día, y es lo que interesa destacar a Marcus en su artículo titulado "Ethnography in/of the World System: The Emergence of Multi-sited Ethnography" (Marcus 1995) con el que voy a terminar, es la experiencia de un mundo parcialmenrte ordenado con arreglo a sistemas locales de producción de sentido y parcialmente ordenado con arreglo a las disposiciones de un sistema global que, en algunas esferas, como la del mercado, presenta dimensiones planetarias.

Aunque este cruzamiento parcial de sitios locales y sitios globales, que Néstor García Canclini denomina "glocales", puede no ser tan nuevo (desde mi punto de vista, trabajos clásicos de la Antropología como La gran transformación de Karl Polanyi resultarían incomprensibles sin una perspectiva de globalización), lo que sí parece ser un hecho es que, en las últimas décadas, cualquier etnografía razonable debe partir de una crítica del concepto insular de cultura, subrayando lo que quizás precisamente este concepto ha tenido y tiene de mayor valor: su dimensión comunicativa, intersubjetiva, y por tanto, en un sentido teórico, interlocal. Hoy en día sabemos que es sencillamente imposible dar cuenta adecuada de cualquier realidad humana sin incorporar a nuestro recorrido por el contexto estructuras y procesos cuya génesis, funcionamiento y eficacia se sitúan en órdenes institucionales externos (más o menos lejanos) a cualquier orden institucional local. Las cosas, hoy en día, nunca suceden solo aquí. Puede ser bien cierto que esto siempre haya sido así, en la medida en que el ser humano se constituye a condición de algún desplazamiento. En todo caso, hoy más que nunca conviene plantearse cómo se las apaña la etnografía para introducir las dimensiones translocales (o globales) imprescindibles para hacer sus datos inteligibles. $\mathrm{Y}$ aunque es cierto que una formulación primaria de nuestro método es distinguir entre el trabajo de campo y la etnografía, yo estaría dispuesto a asegurar que, hasta cierto punto, el ejercicio necesariamente localizado del trabajo de campo, su espacio-tiempo definido, puede inducir a teñir de localismo la producción argumental, cuyo espacio-tiempo aspira a la deslocalización y la generalización. Parafraseando de nuevo a Geertz, los etnógrafos no estudian una comunidad, sino que estudian determinados problemas generales en comunidades; pero yo añadiría: a fuerza de tener que estar entre los miembros de alguna comunidad, corren un enorme riesgo de abandonar la perspectiva generalista de sus argumentaciones, por la perspectiva localista que arrastran sus observaciones. Hoy en día no podemos correr este riesgo.

George Marcus da forma a este problema glosando un nutrido número de etnografías de los últimos años (su artículo fue publicado en 1995), 
y mostrando cómo en estos trabajos se aborda el problema de la relación entre el sistema y el mundo de la vida (Marcus 1995: 95). En particular, se ocupa de lo que a su juicio es una característica forma de producción etnográfica de la tardomodernidad, que denomina con la etiqueta general de etnografía multisituada:

Esta etnografía móvil toma trayectorias inesperadas al trazar una formación cultural a través de y en múltiples sitios de actividad: tales trayectorias desestabilizan la distinción, por ejemplo, entre mundo de la vida y sistema, por la que la mayor parte de la etnografía ha sido concebida. Precisamente en la medida en que de este modo se investiga y construye etnográficamente los mundos de la vida de sujetos diversamente situados, también se construyen etnográficamente aspectos del sistema mismo a través de las asociaciones y conexiones que sugiere entre los sitios (Marcus 1995: 96).

Desde luego que este planteamiento de una etnografía multisituada recuerda morfológicamente a las etnologías de Marcel Mauss y de Tylor (desde Dahomey hasta Hawaii); y en el extremo uno podría plantearse si la etnografía ha dejado de ser alguna vez multi-situada, en la medida en que la multiplicación y diversificación de sus fuentes de datos ha sido siempre una de sus aspiraciones centrales. Pero debemos recordar que el Ensayo sobre los dones no está fundado en el trabajo de campo del propio Mauss, y que algo de razonable debía de haber en la clásica distinción pre-malinowskiana entre etnografía y etnología, que la tradición francesa ha seguido manteniendo, al menos teóricamente, mucho después de Malinowski. A riesgo de ponerme pesado, lo que esta distinción tiene de razonable es que alerta sobre la tentación de localismo que se preforma en la práctica de campo. De manera que lo que interesa a Marcus es destacar las estrategias de deslocalización y dislocación que la moderna etnografía practica, no ya en la reconstrucción teórica (inevitablemente comparativa y etnológica), sino en la producción misma de los datos de campo. Estas estrategias no pueden ya dar por sentada la existencia de la cultura, en el sentido insular de la palabra, como un locus unitario de reglas para una comunidad delimitada: "cultura" (y con ella cualquier noción de totalidad que la acompañe) se ha desplazado decisivamente al nivel del lenguaje analítico, al nivel del discurso del investigador (un lugar en el que, a mi juicio, siempre debió estar), de manera que, una vez incorporada una estrategia multisituada, resulta ya inviable esa trampa esencializadora a la que tan acostumbrados estamos, que consiste en tomar, por ejemplo, un etnónimo como descriptor adecuado de la "cultura" de una comunidad (la cultura mediterránea, las culturas nórdicas, los Nuer, los Inuit). Nada de esto tiene ya sentido fuera de la perspectiva interna 
de los discursos nativos, entre los que se encuentran las objetivaciones nada desdeñables (y nada locales) que practican los sistemas expertos político-administrativos y jurídicos. Lo que encontramos en el campo no son culturas integradas y delimitadas, sino sujetos que en sus prácticas cotidianas ponen en juego local una multiplicidad de códigos relativamente restringidos y relativamente elaborados, relativamente inmediatos a su experiencia y relativamente apartados de ella, relativamente familiares y relativamente extraños; naturalmente, cada sujeto se las apaña para dar sentido a ese jaleo (cada sujeto busca a su manera la totalidad). Pero si buscamos en ese jaleo algún conocimiento antropológico, los únicos responsables de tal tarea constructiva de sentido somos nosotros al poner en juego nuestra propia intuición teórica, y al perseguir literalmente a nuestros sujetos, situación tras situación, por el recorrido de un contexto que incluirá escenas de familia, ceremonias de amistad y rituales de pueblo; pero también, a buen seguro, despachos oficiales, pasillos, escuelas, planificaciones documentales y textos jurídicos. Pues en esto consiste nuestra vida.

Para la etnografía esto significa que el sistema mundo no es el marco teórico holísticamente constituido que da contexto al estudio contemporáneo de las gentes o sujetos locales observados de cerca por los etnógrafos, sino que se convierte, a pedazos, en parte integral de objetos de estudio discontinuos, multisituados, y está encastrado [embedded] en ellos (Marcus 1995: 97).

En este panorama, el investigador se comporta como el héroe de película que dice la frase proverbial: "siga a ese taxi". Este esquema de seguimiento, cuando no de persecución, de un hilo conductor de la trama argumental de la etnografía en el campo es la característica común, en términos operacionales, del modo de construir totalidad de la moderna etnografía multisituada. Marcus resume algunas de estas estrategias: Siga a la gente; siga a la cosa; siga a la metáfora; siga la trama, la historia, la alegoría; siga la vida o la biografía; siga el conflicto (ibid:: 105 ss.).

La investigación multi-situada está diseñada alrededor de cadenas, caminos, hilos, conjunciones, o yuxtaposiciones de localizaciones en las que el etnógrafo establece alguna forma de presencia literal, física, con una lógica explícita y patente de asociación o conexión entre los sitios que de hecho define el argumento de la etnografía (Marcus 1995: 105).

He propuesto un trayecto que evoca diferentes imágenes del todo con la intención fundamental de subrayar los siguientes argumentos: en pri- 
mer lugar, que como herramienta metodológica el holismo es inseparable de los lenguajes teóricos y morales que nos nutren. En segundo lugar, que la totalidad es construida, cualquiera que sea nuestra intención gnoseológica (desde el diseño de mapas culturales a escala planetaria al estilo de Murdock, hasta la comprensión holística de problemas específicos del mundo moderno en sujetos precisos); y que tal construcción se ve preformada doblemente, desde nuestras ideas teóricas y desde nuestras prácticas de campo. En tercer lugar, que el holismo es intencional, o sea que la totalidad nunca es alcanzable por completo. En cuarto lugar, que una ciencia social holística debe sustentarse, como mínimo, en una comprensión semiótica de la sociedad y la cultura, pues es la condición semiótica de nuestra especie la que configura nuestro modo particular de construir relaciones sociales y de experiencia, y puesto que el holismo conduce básicamente a explorar esa clase de relaciones. En quinto lugar, que una ciencia social holística es, seguramente, una ciencia social crítica, alterna, descentrada, y hasta cierto punto excéntrica, pues en la génesis de nuestro holismo metodológico se encuentra también el reconocimiento de nuestro individualismo moral y nuestra búsqueda de modelos alternos de experiencia. Y, finalmente, que construir una totalidad es recorrer un contexto de prácticas humanas, incluso cuando este contexto se presenta retóricamente, como en los escenarios de "globalización", como si estuviera producido al margen de toda práctica, un Deus ex machina de nuestra condición tardomoderna. La intención holística nos incita, incluso en estos casos, a considerar que una ciencia social a la altura del Todo es ante todo una ciencia social a la altura del ser humano y de sus circunstancias.

\section{BIBLIOGRAFÍA CITADA}

Barcellona, Pietro. 1992. Postmodernidad y comunidad. El regreso de la vinculación social. Madrid: Trotta.

DUMONT, LOUIS. 1987 [1980]. "El valor en los modernos y en los otros", en Ensayos sobre el individualismo: 239-275. Madrid: Alianza.

FERNANDEZ, JAMES W. 1986. "The Argument of Images and the Experience of Returning to the Whole", en V.W. Turner y E. M. Bruner (eds.), The Anthropology of Experience: 159-187. Chicago: The University of Chicago Press.

MALINOWSKI, BRONISLAw. 1984a [1923]. "El problema del significado en las lenguas primitivas", en C. K. Odgen y I. A. Richards (eds.), El significado del significado. Barcelona: Paidós.

- 1984b [1944]. Una teoría cientifica de la cultura. Madrid: Sarpe.

Marcus, GeORGE E. 1995. "Ethnography in/of the World System: The Emergence of Multi-sited Ethnography". Annual Review of Anthropology 24: 95-117. 
Mauss, MarCel. 1979 [1923-1924]. "Ensayo sobre los dones: motivo y forma del cambio en las sociedades primitivas", en Sociología y Antropología: 155-268. Madrid: Tecnos.

TYlor, EDWARD BuRnetT. 1977 [1873]. Cultura primitiva. Madrid: Ayuso.

Velasco, Honorio y Ángel DíAz De Rada. 1997. La lógica de la investigación etnográfica. Madrid: Trotta. 